\title{
Age at Diagnosis and Seasonal Variation in the Onset of Insulin-Dependent Diabetes in Chile (Southern Hemisphere)
}

\author{
P. Durruty, F. Ruiz, and M. García de los Ríos \\ Department of Medicine, Nutrition and Diabetes Section, San Juan de Dios Hospital, Faculty of Medicine, University of Chile, \\ Santiago, Chile
}

Summary. The age at diagnosis, sex, and the date of both the diagnosis (month - year) and the onset of symptoms of 525 insulin-dependent diabetic patients, under 30 years of age at the time of diagnosis, were collected retrospectively from hospital records. The patients came from Chilean cities located in the Central Zone: Santiago $(87 \%)$ and Temuco - Concepcion (13\%). The age at diagnosis showed a bimodal distribution up to 19 years of age, with the main peak at 12 years and another at 6 years. The female peak preceded the male peak by 1 to 2 years. The onset of symptoms showed a seasonal variation, with the highest frequency in winter and the lowest in spring $(\mathrm{P}<0.01)$. There was also a significant variation in the time of diagnosis, especially in the 0-19 age group: most cases were diagnosed in winter (June, July) with the lowest number in summer (December).

Key words: Diagnosis, seasonal variation, diabetes mellitus, insulin-dependent.

Great interest has recently been aroused by epidemiological studies of insulin-dependent diabetes which were carried out in the hope that some non-genetic aetiological factors might be revealed [1].

In several investigations $[2,3,4]$ the onset of the disease occurred most frequently between 5 and 7 years and between 10 and 14 years of age. Furthermore, a seasonal variation in the incidence of insulin dependent diabetes has been reported, the greatest frequency being in autumn and winter, the least in summer $[5,6,7,8,9]$. These reports have all come from the Northern hemisphere. In order to see if a similar pattern was true for the Southern hemisphere we have investigated the age and seasonal incidence of insulin-dependent diabetes in a community in Chile.

\section{Material and Methods}

Chile has three important characteristics related to this study: $70 \%$ of the country's population lives in the Central Zone, $90 \%$ of the medical care is given, free of charge, in public hospitals and the seasons can be clearly distinguished: summer (December, January, February), autumn (March, April, May), winter (June, July, August) and spring (September, October, November).

The study was made in 3 highly populated cities of the Central Zone: Santiago, which contains $33 \%$ of the population, and Temuco and Concepcion. The hospital records of all insulin dependent diabetic patients from 7 public hospitals and 4 private clinics (that give medical care to a high number of diabetic patients who are not affiliated to the Public Health System) were reviewed, in order to obtain the following data: age at diagnosis, date of diagnosis and of onset of symptoms.

Data were collected from 525 insulin dependent diabetics ( $50.5 \%$ male) diagnosed before the age of 30 during the years 1953 to 1978 ; in 72 there was no information about onset of symptoms.

Of the total number of cases $87 \%$ came from Santiago; $85 \%$ were from public hospitals, $67 \%$ from our own institution.

The data were coded and analyzed by computer. The binomial test was used to calculate statistical significance.

\section{Results}

\section{Age at Diagnosis}

The distribution of age at diagnosis (Figure 1) shows a main peak at age 12 and a smaller peak at 6 years. The 12 year peak deviates significantly from the average $(P<0.0001)$. Between 20 and 30 years two small peaks appear at 22 and 26 . In girls the main peak appears between 10 and 11 years, in boys between 12 and 14. 


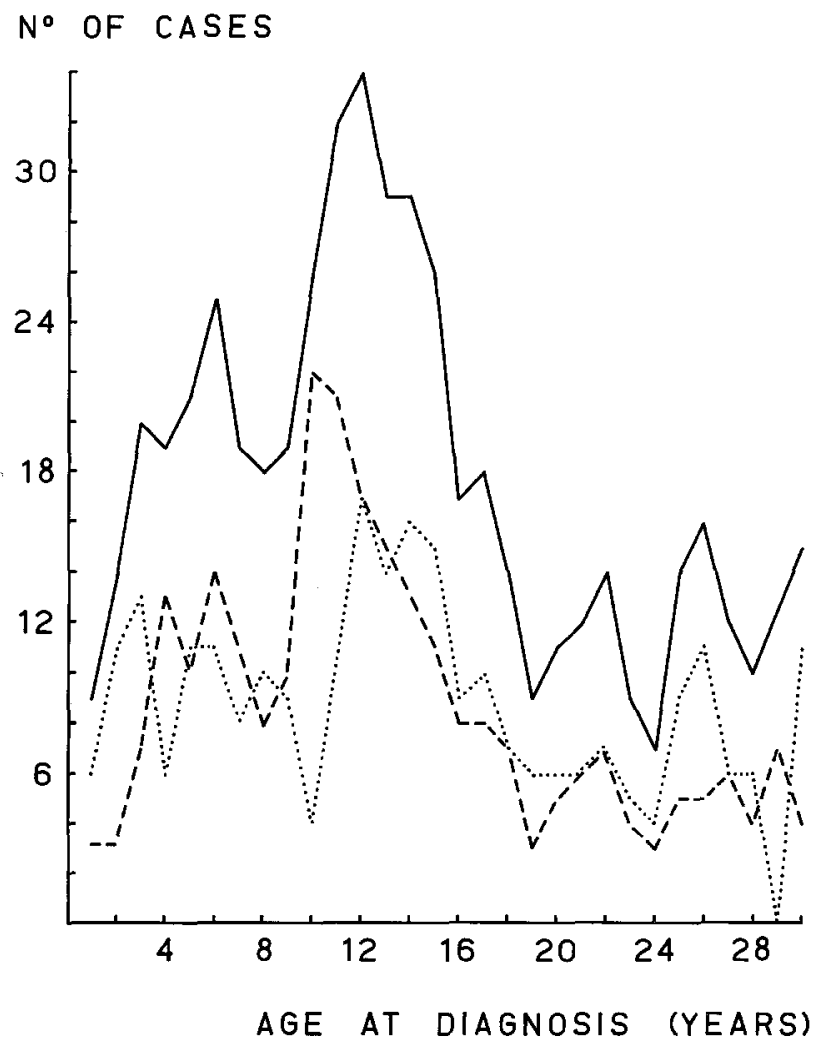

Fig. 1. Age at diagnosis of 525 insulin-dependent diabetic patients. 260 women and 265 men. _ total, --- women, $\cdots$ men

\section{Seasonal Variation}

The distribution of month of onset of symptoms is shown in Figure 2. A significant peak is seen in June $(\mathrm{P}<0.01)$ and another (insignificant) one in January.

The distribution of the total number of cases by month of diagnosis presents the highest frequency in June and July $(P<0.01)$; it begins to fall in August and reaches a minimum in December. Two small non-significant peaks appear in January and March.

A clear seasonal tendency was observed. In Figure 3 it can be seen that the onset of symptoms shows seasonal variations in all groups, the lowest frequency in spring $(P<0.01)$, increasing in summer and in autumn and reaching a maximum in winter $(\mathrm{P}$ $<0.01$ ). The same variation is seen in the $0-19$ year and 20-29 year groups. The frequency of diagnosis in the $0-19$ year group is lowest in summer $(P<0.01)$, rises slightly in autumn, reaches a maximum in winter $(\mathrm{P}<0.0001)$ and falls in spring. Patients over 19 years of age did not show this seasonal change.
$N^{\circ}$ OF CASES

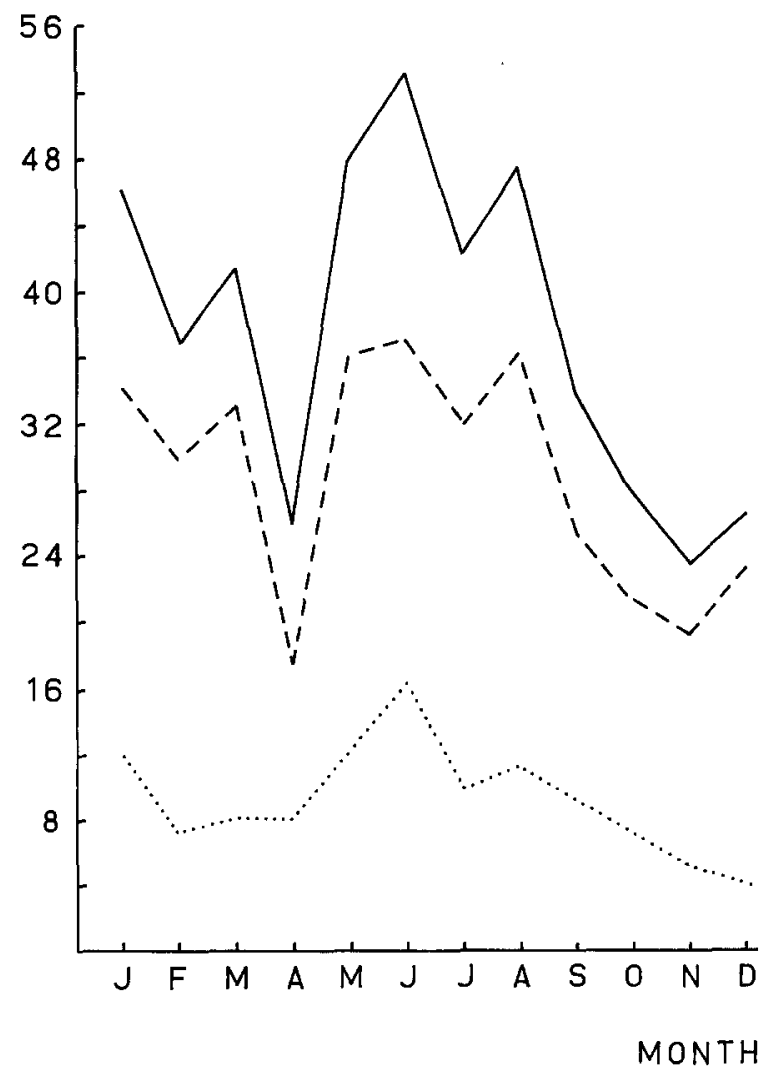

Fig. 2. Month of onset of symptoms 453 insulin-dependent diabetic patients under 30 years of age at diagnosis: 344 under 19 years and 109 over 19 years. — total, - - - 0-19 years, ..... 20-30 years

\section{Discussion}

This study was made retrospectively from a review of hospital records of insulin dependent diabetics. We believe the subjects studied are representative of our insulin dependent diabetics since all the records of insulin dependent diabetic patients from hospital and private clinics, where most diabetics receive medical care, were reviewed and all those which contained the required data were coded.

In this study, as in previous reports from our clinic $[10,11,12]$, there was an equal proportion of men and women. This differs from publications from Europe which show a higher frequency of insulin dependent diabetes in males $[2,4]$.

The bimodal distribution of age of onset in our cases with a main peak near puberty (girls earlier than boys) and a smaller one at the beginning of school age, is similar to that reported from Europe $[2,3,4]$. These peaks have been associated with different factors. Some investigators $[3,4]$ think that the higher frequency of diabetes observed at about 6 
$N^{\circ}$ OF CASES

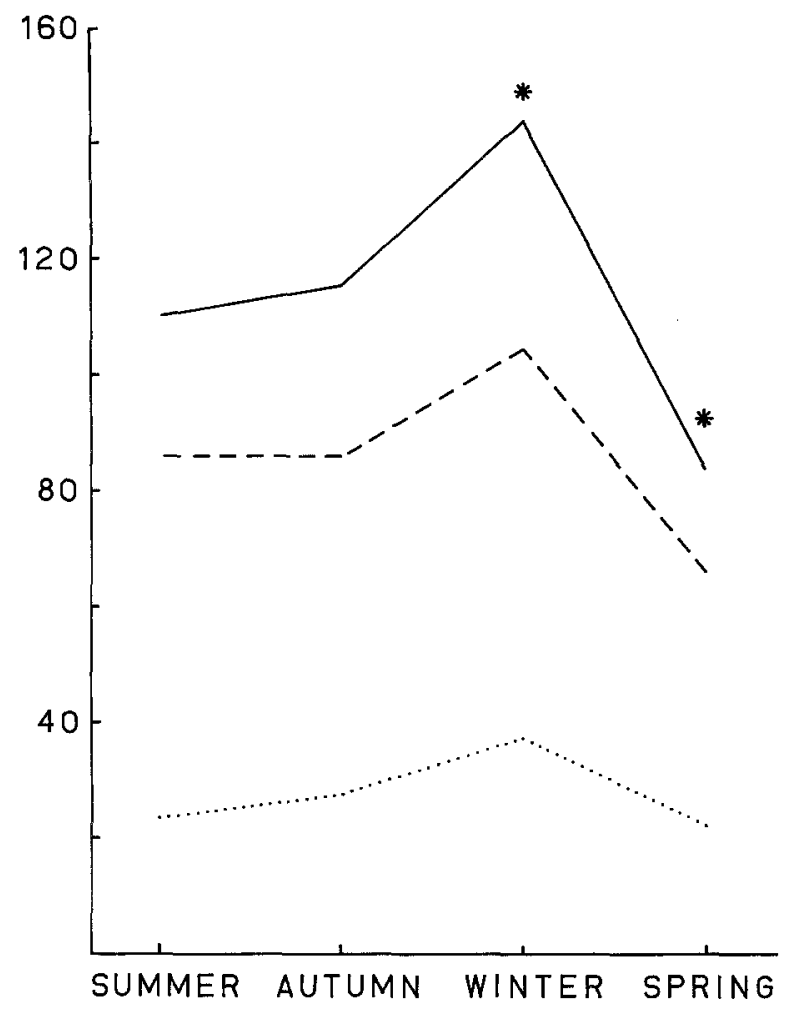

Fig. 3. Seasonal variation in the onset of symptoms of insulindependent diabetic patients under 30 years of age at diagnosis. $* \mathrm{P}<0.01$. - total, $---0-19$ years, $\cdots 2$ 20-30 years
Of all the years studied, the highest number of cases was recorded in 1976 (44 cases), the year in which an investigation was carried out in Santiago concerning the beginning of insulin dependent diabetes mellitus; in that year too the characteristic seasonal variation was seen.

The lower number of cases diagnosed during the summer has been attributed to the lack of medical care during these months [2]. However in our study the onset of symptoms as well as the time of diagnosis was also reduced in summer. In $78 \%$ of our cases the period between the onset of symptoms and diagnosis was less than one month, so it is very improbable that lack of medical care could account for the low frequency of cases in summer.

According to some authors $[4,7]$ viral infections might be the main factor responsible for the seasonal variation, since they show the same seasonal changes as diabetes, even though no direct relation has yet been established.

The results of this study support the hypothesis that environmental factors, the nature of which has not yet been determined, are important in the onset of insulin dependent diabetes.

Acknowledgements. We thank Dr. O. Veitt, Dr. G. Arias, Dr. J. Donoso, Dr. H. Pumarino, Dr. A. Emparanza and Dr. J. Tapia for information and Dr. L. Rodriguez for his help with the statistics.

\section{References}

years of age could be related to the beginning of primary education, since major environmental changes occur at this stage of childhood. In our country the beginning of school education in both sexes is at 6 [13], but in this study a marked peak was observed at this age only in girls. This suggests there is probably no association between starting school and the onset of diabetes. The age of highest frequency of diabetes in girls coincided with the age of menarche [14]; in boys the peak appeared later, like puberty [15].

The higher number of cases diagnosed and with onset of symptoms during the coldest months, has also been observed in countries in the Northern hemisphere - Denmark [2] Sweden [3], Great Britain [7] and U.S. A. [8, 9]. This monthly variation in the number of cases became even more evident when they were grouped by season; a remarkable difference in frequency emerged in the cold and warm months. This seasonal variation was observed in those diagnosed before 19 years of age, especially in the 9-19 years subgroup ( 256 cases).
1. Tattersall, R. B., Pyke, D. A.: Diabetes in identical twins. Lancet 1972 II, $1120-1125$

2. Christau, B., Kromann, H., Ortved Andersen, O., Christy, M., Buschard, K., Arnung, K., Højland Kristensen, I., Peitersen, B., Steinrud, Y., Nerup, J.: Incidence, seasonal and geographical patterns of juvenile-onset insulin-dependent diabetes mellitus in Denmark. Diabetologia 13, 1-4 (1977)

3. Sterky, G., Holmgren, G., Gustavson, K. H., Larsson, Y., Wall, S.: The incidence of diabetes mellitus in Swedish children 1970-1975. Acta Paediatr. Scand. 67, 139-143 (1978)

4. Bloom, A., Hayes, T. M., Gamble, D. R.: Register of newly diagnosed diabetic children. Br. Med. J. 1975 III, 580-583

5. Adams, S. F.: The seasonal variation in the onset of acute diabetes. Arch. Intern. Med. 37, 861-864 (1926)

6. Lestradet, H., Besse, J.: Prevalence and incidence of diabetes mellitus in children and adolescents. Acta Paediatr. Belg. 30, 123-127 (1977)

7. Gamble, D. R., Taylor, K. W.: Seasonal incidence of diabetes mellitus. Br. Med. J. 1969 III, 631-633

8. MacMillan, D. R., Kotoyan, M., Zeidner, D., Hafezi, B.: Seasonal variation in the onset of diabetes in children. Pediatrics 59, 113-115 (1977)

9. Kyllo, C. J., Nutall, F. Q.: Prevalence of diabetes mellitus in school age children in Minnesota. Diabetes 27, 57-60 (1978)

10. Mella, I., García de los Ríos, M., López, G., Schilling, E.: Infantile diabetes. Rev. Chil. Pediatr. 44, 207-214 (1973) Lundmark, K. M., Nilsson, K. O., Samuelson, G., Thalme, B., 
11. García de los Ríos, M., Valiente, S., Canessa, I., Mella, I., Taucher, E.: Degenerating complications and survival in diabetic patients. Rev. Med. Chil. 100, 733-740 (1972)

12. Mella, I., García de los Ríos, M., Tapia, J., Carrasco, E., Fonseca, B.: Growth in diabetic children. Rev. Med. Chil. (In press)

13. Tacla, O.: Demographic survey of Chile and its evolution in the present century. Santiago-Chile: National Institute of Statistics 1975

14. Avendaño, A., Valenzuela, C., Patri, A., Cerda, M., Figueroa, I., Villalón, H., Serra, G., Saavedra, I., Wilder, E.: Antropometry of Chilean school children of the northern area of Santiago. Cuadernos Méd. Soc. 16, 5-21 (1975)
15. Pumarino, H.: Endocrinology and metabolism. Pumarino, $\mathrm{H}$. (Ed.), p. 545. Chile: Andrés Bello 1976

Received: April 5, 1979,

and in revised form: June 27, 1979

Dr. M. García de los Ríos

Departamento de Nutricion y Diabetes

Servicio de Medícina

Hospital San Juan de Dios

Casilla 5584

Santiago, Chile 